\title{
Study of the Interactive Effects of Calcium and Abscisic Acid on Drought Stressed Triticum aestivum Seedlings
}

\author{
Nasser Sewelam ${ }^{1,2 \#, ~ S a m h a ~ D o w i d a r ~}{ }^{1}$, Essam Alden Abo-Kassem ${ }^{1}$ and Sherien \\ Sobhy ${ }^{1}$ \\ ${ }^{1}$ Botany Department, Faculty of Science, Tanta University, Tanta and ${ }^{2}$ Basic \& Applied \\ Sciences School, Egypt-Japan University of Science and Technology, Alexandria, \\ Egypt.
}

\begin{abstract}
N THEIR natural habitats, plants are continuously subjected to many severe environmental challenges including drought. In this study, the effects of drought on Triticum aestivum seedlings were assessed, and the alleviating roles and interactive effects of calcium $\left(\mathrm{Ca}^{2+}\right)$ and abscisic acid (ABA) to drought stress were studied. The results showed that pretreating wheat seedlings with calcium chloride $\left(\mathrm{CaCl}_{2}\right)$ or $\mathrm{ABA}$ led to alleviating most of the negative effects of $20 \%$ polyethylene glycol (PEG, as a drought imposing agent). $\mathrm{Ca}^{2+}$ improved the growth criteria, photosynthetic activity, but ABA had no significant effects on growth parameters. $\mathrm{Ca}^{2+}$ or ABA pretreatments have alleviated the toxic effects of the drought-induced oxidative stress which was marked with the reduction of MDA content. $\mathrm{Ca}^{2+}$ and/or ABA reduced the PEGinduced catalase activity, and ascorbic acid content. The use of lanthanum chloride $\left(\mathrm{LaCl}_{3}\right)$ as a calcium channel blocker has confirmed the role of $\mathrm{Ca}^{2+}$ in ameliorating the drought effects on plant. This study revealed that the application of $\mathrm{Ca}^{2+}$ has increased the endogenous ABA level of the treated seedlings to a high extent exceeding that of PEG treatment itself suggesting that $\mathrm{ABA}$ requires $\mathrm{Ca}^{2+}$ ions for its induction, and $\mathrm{ABA}$ is working downstream from $\mathrm{Ca}^{2+}$ in the relevant signaling pathways activated by drought stress. The alleviating effects of $\mathrm{Ca}^{2+}$ was prolonged to the yield stage. Overall, our results suggest that $\mathrm{Ca}^{2+}(10 \mathrm{mM})$, and with a less extend ABA $(0.1 \mathrm{mM})$, represent signaling agents that can partially alleviate drought stress in plants growing in dry environments.
\end{abstract}

Keywords: Drought, Polyethylene glycol, Calcium signaling, Abscisic acid, Lanthanum chloride, Antioxidants.

\section{Introduction}

Plants are subjected to several environmental stresses that harmfully affect growth, metabolism, and yield. Drought triggers a wide variety of plant responses, ranging from cellular metabolism to changes in growth rates and crop yields (Anjum et al., 2011). Drought stress is a limiting factor at the initial phase of plant growth and establishment (Shao et al., 2008). Cell growth is considered as one of the most drought-sensitive processes due to the reduction in turgor pressure. It was reported that drought causes impaired mitosis, cell elongation and expansion resulting in reduced growth and yield traits (Hussein et al., 2008).

During events of suboptimal conditions, such as drought, different pathways can be affected differently which may make cellular homeostasis become disrupted. This process is usually accompanied by the formation of reactive oxygen species (ROS) (Mittler, 2002). Plants are well adapted for minimizing the damage that could be induced by the ROS under natural growth conditions. However, ROS toxicity emerges when their production exceeds the quenching capacity of the protective systems due to environmental adverse conditions (Foyer \& Noctor, 2003). The toxic levels of ROS can cause damage to DNA, proteins, lipids, chlorophyll and almost every other organic constituents of the living cell (Jiang \& Zhang, 2001). Various plant species have an efficient enzymatic antioxidant system such as catalase, ascorbate peroxidase and glutathione reductase. In addition, plants have non-enzymatic antioxidants such as ascorbic acid (ASA) and glutathione (GSH). These antioxidant defense systems control the cascades of uncontrolled oxidation processes and protect plant cells from oxidative damage by scavenging ROS (Sewelam et al., 2016). 
Plants produce several signaling molecules, including calcium and abscisic acid, to orchestrate various stress responses and to cope with the negative effects of drought and other environmental stresses. As a second messenger in a wide range of signaling pathways, calcium connects the perception of different stimuli and stresses to their downstream cellular responses (Sanders et al., 2002 and Gilroy et al., 2016). Exogenous $\mathrm{Ca}^{2+}$ can enhance plant drought resistance and protect the structure of cellular plasma membranes (Chengbin et al., 2013). It maintains normal photosynthesis and regulates the metabolism of plant hormones and other important chemicals (Miqyass et al., 2007 and Gilroy et al., 2016). In addition, as a second messenger, cellular $\mathrm{Ca}^{2+}$ also transmits drought signals, thus regulating the physiological responses induced by drought stress (Tuberosa et al., 2007).

Various plant hormones, including ABA, have a broad effect on developmental processes and stress responses in plants (Fujita et al. 2006 and Wasternack, 2007). The complex regulatory and interaction networks occurring between hormonesignaling pathways allows the plant to activate appropriate responses to different types of stimuli (McSteen \& Zhao, 2008 and Bari \& Jones, 2009). It was reported that endogenous ABA concentrations increase under drought stress due to induction of ABA biosynthesis genes (Taji et al., 2001). The increase in ABA level reprograms the expression patterns of many genes to regulate water relations through adjustment of cellular osmotic pressure. Furthermore, the increase in ABA level is a central player controlling downstream responses essential for adaptation to different stresses, especially drought (Davies et al., 2002 and Giuliani et al., 2005). These responses include changes in stomatal conductance (closure of stomata), osmolyte accumulation, gene expression, a reduced leaf canopy, deeper root growth and changes in root system architecture (Davies et al., 2002; Giuliani et al., 2005; Lee et al., 2013 and An et al., 2016).

To impose water stress in plants, several methods ranging from water regimes, withdrawal of water from plants, to the use of chemicals such as polyethylene glycol (PEG), mannitol, etc., have been employed. It has been reasonably well established that polyethylene glycol-induced water stress mimics that caused by withdrawal of water from plants (Ravi et al., 2011). PEG of high molecular weights have been long used to stimulate drought stress in plants as nonpenetrating osmotic agents lowering the water potential in a way similar to soil drying (Larher et al., 1993). In addition, it has been reported that PEG induces significant water stress in plants without having any toxic effects (Emmerich \& Hardegree, 1990). In the current study, PEG treatment was applied as a drought stress agent. To evaluate the roles of calcium and $\mathrm{ABA}$ in alleviating the effects of drought stress, wheat seedling were pretreated with calcium and/ or ABA before treating with PEG. The present results suggested an important role for calcium in minimizing the negative effects of drought stress on wheat seedlings and in improving the overall growth. Also, our data revealed that calcium is working upstream from ABA during the signaling pathways involved in response to drought stress.

\section{Materials and Methods}

\section{Plant material and growth conditions}

The experiments in this study were cried out on wheat (Triticum aestivum L.) grains cultivar Gmiza 9. The grains were obtained from the Agricultural Research Center, Egypt. Before sowing, the grains were selected to be uniform in size and shape, sterilized in commercial clorox (1:1) for $5 \mathrm{~min}$, and then washed with distilled water three times. For seedling stage, wheat grains were sown in plastic pots $(10 \mathrm{~cm}$ diameter and $5 \mathrm{~cm}$ depth) filled with sand (about $100 \mathrm{~g}$ per pot). The sand has been washed with $\mathrm{HCl} / \mathrm{H}_{2} \mathrm{O}$ (1:1), and then washed three times with distilled water before sowing. Ten grains were sown per pot, irrigated with distilled water and left to grow for eight days in growth chamber under controlled conditions $\left(12 / 12\right.$ day/night at $\left.25^{\circ} \mathrm{C} / 15^{\circ} \mathrm{C} \pm 2^{\circ} \mathrm{C}\right)$, left to germinate and grow for eight days before the treatment. For yield experiment, 20 grains were sown in each plastic pots $(40 \mathrm{~cm}$ diameter and $45 \mathrm{~cm}$ depth), filled with $20 \mathrm{~kg}$ clay-sandy soil $(2: 1 \mathrm{w} / \mathrm{w})$ and left to grow at the greenhouse and irrigated with tap water once weekly during the experimental period.

\section{Treatments}

Based on a preliminary experiment; the sublethal concentration of PEG 6000 was selected to be $20 \%$, and the proper concentration of calcium was $10 \mathrm{mM}$. While, the applied concentrations of $\mathrm{ABA}$ and $\mathrm{LaCl}_{3}$ were selected based on experiments from the literature to be $0.1 \mathrm{mM}$ for ABA (Tracy et al., 1993) and $5 \mathrm{mM}$ for 
$\mathrm{LaCl}_{3}$ (Francisco \& Juan, 2014). Eight different treatment combinations (three replicates each) were applied as represented in Fig. 1. For yield measurements, wheat grains were grown under the same treatments as described above (after excluding the ABA treatments), and left to grow till the yield stage.

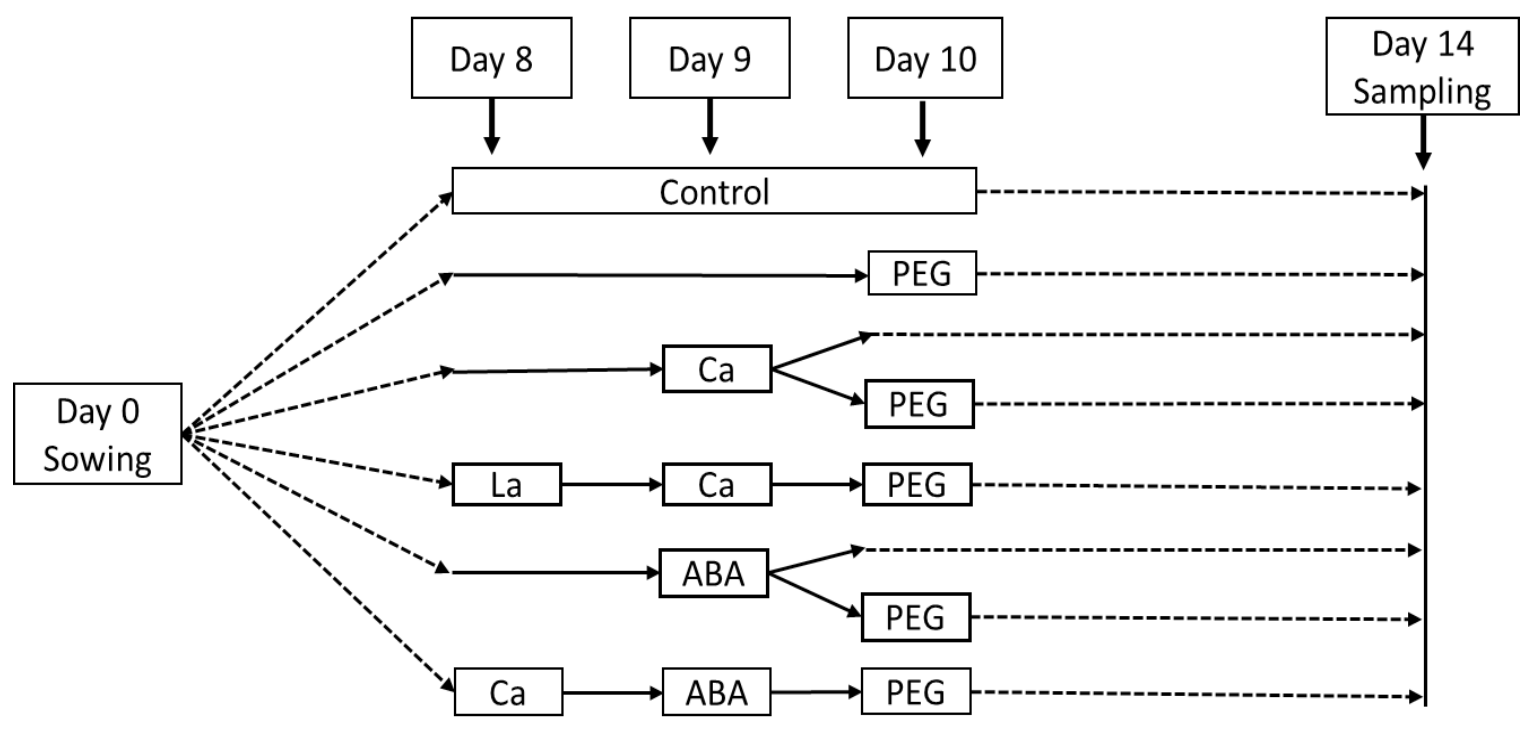

Fig. 1. A schematic diagram explaining the treatments and sampling procedures.

Plant analyses

For all measurements at the seedling stage, samples were collected four days after the PEG treatment. Yield analysis was carried out after ripening (about 120 days).

\section{Growth criteria}

Wheat seedlings were harvested and separated into shoots and roots, and weighed directly for fresh weights (FW). To determine the dry weights (DW), plant parts were dried at $60^{\circ} \mathrm{C}$ until constant weight was reached.

\section{Measurement of photosynthetic efficiency}

Photosynthetic efficiency (Fv/Fm) of wheat leaves was measured with a portable pulse amplitude modulation (PAM) fluorimeter (PerkinElmer, UK). The measurement of photosynthetic efficiency, on the adaxial leaf surface, was carried out as described by Gonçalves $\&$ Santos (2005). The leaves were dark-adapted for $30 \mathrm{~min}$, then they were initially exposed to the weak modulated measuring beam $\left(<0.1 \mathrm{umol} \mathrm{m}^{-2}\right.$ $\left.\mathrm{s}^{-1}\right)$ to estimate the initial fluorescence $\left(\mathrm{F}_{0}\right)$ when the PS II reaction centers are opening (oxidized). Thereafter, the leaf was exposed to an $800 \mathrm{~ms}$ saturation pulse of high-intensity $(>10000 \mu \mathrm{mol} /$ $\mathrm{m}^{2}$ per $\mathrm{s}$ white light), to produce a transient closure (reduction) of the PS II reaction centers, at this point the maximum fluorescence $(\mathrm{Fm})$ was achieved. Three replicates of each treatment were measured. The fluorescence values of the initial fluorescence $\left(\mathrm{F}_{0}\right)$, the maximal fluorescence $(\mathrm{Fm})$ and the maximum photochemical efficiency of PSII $\left(\mathrm{F}_{\mathrm{v}} / \mathrm{F}_{\mathrm{m}}\right)$ were recorded from the fluorimeter. The variable fluorescence was calculated as follow $\left(\mathrm{F}_{\mathrm{v}}=\mathrm{F}_{\mathrm{m}}-\mathrm{F}_{0}\right)$.

\section{Determination of lipid peroxidation level}

Lipid peroxidation was measured by determining the amount of malondialdehyde (MDA), as a product of peroxidation of the unsaturated fatty acid; linolenic acid (18:3). MDA concentration was estimated by the method of Heath \& Packer (1968). A sample of $0.5 \mathrm{~g}$ fresh leaves was extracted in $10 \mathrm{ml} \mathrm{5 \%}$ $(\mathrm{w} / \mathrm{v})$ trichloroacetic acid. The homogenate was then centrifuged at $4000 \mathrm{rpm}$ for $10 \mathrm{~min}$. The supernatant $(2 \mathrm{ml})$ was mixed with $2 \mathrm{ml}$ of $0.67 \%$ $(\mathrm{w} / \mathrm{v})$ thiobarbaturic acid, and incubated at $95^{\circ} \mathrm{C}$ in a water bath for $20 \mathrm{~min}$ then cooled immediately. Absorbance was read at $532 \mathrm{~nm}$ and $600 \mathrm{~nm}$. MDA concentration ( $\mu \mathrm{M} / \mathrm{g}$ f.wt.) was calculated using the extinction coefficient $\left(155 \mathrm{mM}^{-1} \mathrm{~cm}^{-1}\right)$.

\section{Estimation of catalase activity}

A sample of $0.5 \mathrm{~g}$ fresh plant material was frozen, then homogenized in $8 \mathrm{ml}$ of $50 \mathrm{mM}$ cold phosphate buffer of $\mathrm{pH} 7.00$ (Beauchamp \& Fridovich, 1971). After centrifuging the homogenates for $20 \mathrm{~min}$ at $4000 \mathrm{rpm}$, the 
supernatant was used as a raw extract for enzymatic assay. For measuring catalase activity, a sample of $3 \mathrm{ml}$ of reaction mixture containing $0.1 \mathrm{M}$ sodium phosphate buffer of $\mathrm{pH} \mathrm{7,2} \mathrm{mM}$ $\mathrm{H}_{2} \mathrm{O}_{2}$ content and $0.1 \mathrm{ml}$ enzyme extract, was prepared for the assay (Kato \& Shimizu, 1987). The decrease in $\mathrm{H}_{2} \mathrm{O}_{2}$ was followed as a decline in the absorbance at $240 \mathrm{~nm}$ and the activity was calculated using the extinction coefficient (40 $\mathrm{Mm}^{-1} \mathrm{~cm}^{-1}$ at $240 \mathrm{~nm}$ ), and expressed in units of $\mu \mathrm{M}$ of the substrate converted per min/gram fresh weight.

\section{Estimation of ascorbic acid content}

The non-enzymatic antioxidant, ascorbic acid, was estimated according to Oser (1979). A known weight $(0.1 \mathrm{~g})$ of leaf tissue was homogenized in 5 $\mathrm{ml}$ of $5 \%(\mathrm{w} / \mathrm{v})$ sulfosalicylic acid and centrifuged at $10,000 \mathrm{rpm}$ for $10 \mathrm{~min}$. The reaction mixture for ascorbate consisted of $2 \mathrm{ml} \mathrm{2 \%} \mathrm{Na-molybedate,} 2$ $\mathrm{ml} 0.15 \mathrm{~N} \mathrm{H}_{2} \mathrm{SO}_{4}, 1 \mathrm{ml} 1.5 \mathrm{mM} \mathrm{Na}_{2} \mathrm{HPO}_{4}$ and $1 \mathrm{ml}$ tissue extract. The reaction mixture was incubated at $60^{\circ} \mathrm{C}$ in a water bath for $40 \mathrm{~min}$, cooled and centrifuged at $3000 \mathrm{rpm}$ for $10 \mathrm{~min}$, and then absorbance was measured at $660 \mathrm{~nm}$. Ascorbic acid content was calculated as $\mathrm{mg} / \mathrm{g}$ d.wt. using a prepared calibration curve by ascorbic acid.

\section{Estimation of endogenous ABA levels}

Endogenous ABA level was estimated using Gas-Liquid Chromatography according to Shindy \& Smith (1975).

\section{Yield analyses}

After ripening, about 120 days from sowing, yield criteria were measured, including number of grains per plant and the weight of 1000 grains.

\section{Statistical analysis}

All experimental determinations were replicated. The obtained data represented the mean values. Data obtained were analyzed statistically (Steel \& Torrie, 1980) to determine the degree of significance between treatments. ANOVA (Oneway analysis of variance) method was applied for all data and the LSD (least significant difference) at 0.05 was used to compare the means.

\section{Results}

\section{Growth criteria}

Drought stress has deleterious effects on growth of different plant species. To study the damaging effects of PEG (as a drought initiating substance) on the growth of wheat seedlings and to assess the alleviating roles of $\mathrm{Ca}^{2+}$ and $\mathrm{ABA}$, some of the growth criteria were measured including the fresh and dry weights of shoots and roots. The results indicated that PEG treatment led to a significant decrease in shoot fresh and dry weights where the percentages of the decrease were $15.7 \%$ and $26.7 \%$, respectively, compared with the control. On contrary, PEG significantly increased root fresh and dry weights and the percentages of the increase were $40 \%$ and $16.7 \%$, respectively relative to the control. The treatment with $\mathrm{Ca}^{2+}$ led to a significant increase in fresh weight of shoot and root relative to the control, but it induced a highly significant decrease in shoot dry weights, and had no significant effect on root dry weight (Fig. 2).

The combined treatment of $\mathrm{Ca}^{2+}$ and PEG had no significant effect on shoot fresh weight, but it significantly increased the shoot dry weight when compared with the PEG treatment. At the meantime, there was a highly significant decrease in root fresh and dry weights under $\mathrm{Ca}^{2+}$ and $\mathrm{PEG}$ combined treatment relative to the PEG treatment. Treating wheat seedlings with a combination of $\mathrm{La}^{3+}, \mathrm{Ca}^{2+}$ and PEG resulted in a highly significant decrease in shoot fresh and dry weights, while it significantly increased the fresh and dry weights of root when compared with the combined treatment of $\mathrm{Ca}^{2+}$ and PEG (Fig. 2).

The treatments of ABA (singly, combined with PEG, or with $\mathrm{Ca}^{2+}$ and PEG) led to a significant decrease in both fresh and dry weights of shoot relative to the control. In addition, these treatments decreased root fresh weight compared with the control with the exception of ABA single treatment which had no significant effect on root fresh weight. The ABA single treatment induced a highly significant increase in root dry weight relative to the control, but the other two treatments (ABA and PEG, and $\mathrm{Ca}^{2+}$ with $\mathrm{ABA}$ and PEG) did not induce any significant effect (Fig. 2).

\section{Photosynthetic efficiency $(\mathrm{Fv} / \mathrm{Fm})$}

Photosynthesis is one of the most sensitive physiological processes to drought stress. The changes in photosynthetic efficiency $(\mathrm{Fv} / \mathrm{Fm})$ was measured. As shown in Fig. 3, PEG led to a highly significant decrease in $\mathrm{Fv} / \mathrm{Fm}$ value compared with the control. Meanwhile, the treatments of $\mathrm{Ca}^{2+}$, and the combination of $\mathrm{Ca}^{2+}$ and PEG resulted in a highly significant increases in $\mathrm{Fv} / \mathrm{Fm}$ value relative to the PEG treatment. 

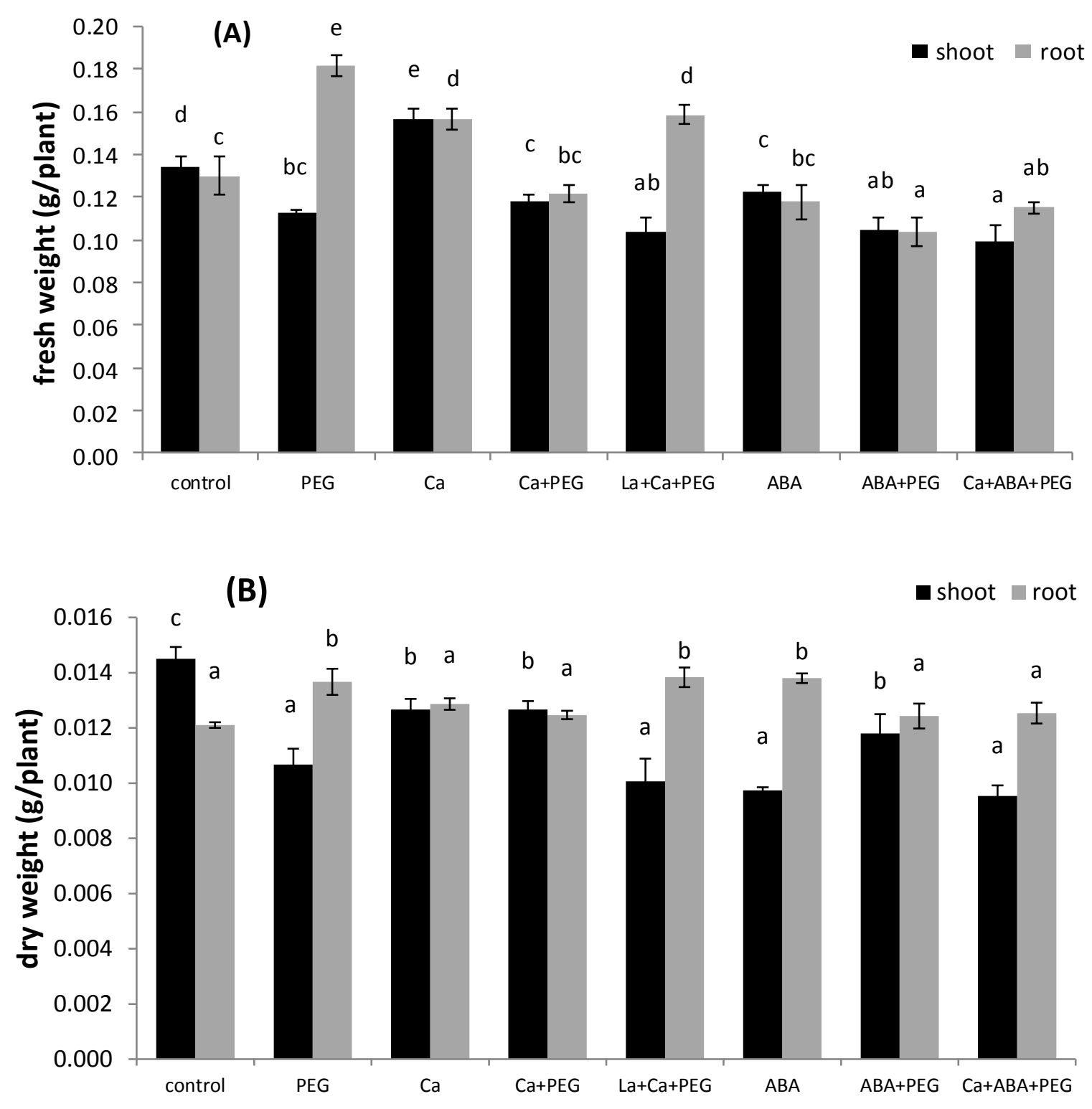

Fig. 2. The changes in shoot and root fresh and dry weights of $20 \%$ PEG-treated 14-day old T. aestivum seedlings with or without a pretreatment of $\mathrm{LaCl}_{3}(5 \mathrm{mM}), \mathrm{CaCl}_{2}(10 \mathrm{mM})$ and/or $\mathrm{ABA}(0.1 \mathrm{mM})$. Three biological replicates per treatment were used. Error bars represent standard deviations. Different letters indicate statistically significant $(\mathbf{P}<0.01)$ differences.

\begin{tabular}{|c|c|c|c|}
\hline \multicolumn{4}{|c|}{ One way ANOVA analysis $(\mathrm{P}<0.01)$} \\
\hline Parameters & LSD & $\mathrm{F}$ & Significance \\
\hline Shoot f.wt. & 0.02 & 41.4 & ** \\
\hline Root f.wt. & 0.01 & 58.8 & $* *$ \\
\hline Shoot d.wt. & 0.001 & 29.1 & $* *$ \\
\hline Root d.wt. & 0.001 & 14.6 & *** \\
\hline
\end{tabular}

** Highly significant 


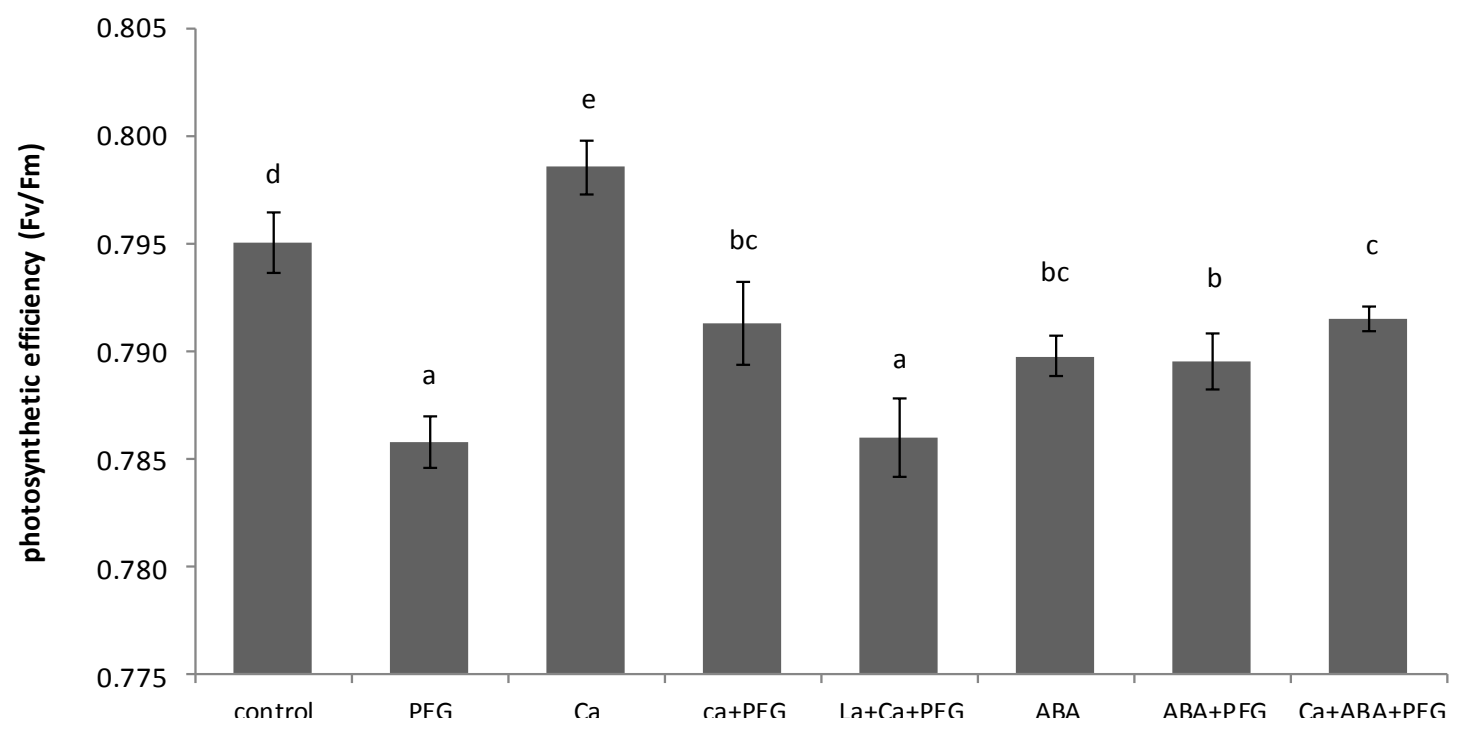

Fig. 3. The changes in photosynthetic efficiency (Fv/Fm) of $20 \%$ PEG-treated 14-day old T. aestivum seedlings with or without a pretreatment of $\mathrm{LaCl}_{3}(5 \mathrm{mM}), \mathrm{CaCl}_{2}(10 \mathrm{mM})$ and/or $\mathrm{ABA}(0.1 \mathrm{mM})$. Three biological replicates per treatment were used. Error bars represent standard deviations. Different letters indicate statistically significant $(\mathbf{P}<\mathbf{0 . 0 1})$ differences.

One way ANOVA analysis $(\mathrm{P}<0.01)$

$\begin{array}{llcc}\text { Parameters } & \text { LSD } & \text { F } & \text { Significance } \\ \text { Photosynthetic efficiency } & 0.002 & 59.88 & * *\end{array}$

** Highly significant.

Interestingly, the combined treatment of $\mathrm{La}^{3+}, \mathrm{Ca}^{2+}$ and PEG didn't induce any significant effect on the FV/Fm value compared with the PEG treatment, but led to a highly significant decrease in the $\mathrm{Fv} / \mathrm{Fm}$ value when compared with the combined treatment of $\mathrm{Ca}^{2+}$ and PEG. However, all treatments of individual ABA or combined with PEG in the presence or absence of $\mathrm{Ca}^{2+}$ indicated a highly significant amelioration of the harmful effects caused by PEG, where photosynthetic efficiency was increased compared with the PEG treatment but still less than the control (Fig. 3).

\section{Oxidative stress level}

Drought stress is known to cause oxidative cell damage by generating ROS. In the current study, the oxidative stress level was monitored via measuring the changes in malondialdehyde (MDA), a lipid peroxidation product. Treating wheat seedlings with PEG induced a highly significant increase in MDA content compared with the control. The magnitude of the increase of MDA with PEG treatment reached $85.9 \%$ when compared with the control (Fig. 4).

On the other hand, treatment with $\mathrm{ABA}$ or $\mathrm{Ca}^{2+}$ resulted in a pronounced decrease in MDA content compared with the control. Moreover, addition of either $\mathrm{ABA}$ or $\mathrm{Ca}^{2+}$ or their combination, followed by supplementation of PEG led to a marked reduction in MDA content when compared with PEG treatment. However, this effect was largely abolished when the $\mathrm{Ca}^{2+}$ treatment was preceded by $\mathrm{La}^{3+}$ treatment where the combined treatment $\mathrm{La}^{3+}, \mathrm{Ca}^{2+}$ and PEG led to a highly significantly increase in MDA relative to the control treatment (Fig. 4).

\section{Antioxidants}

Plant cells have evolved a surveillance antioxidant system to cope with the oxidative damage of ROS produced under various stresses. Here, we studied the changes of the antioxidant enzyme catalase and the antioxidant compound ascorbic acid under drought stress. 


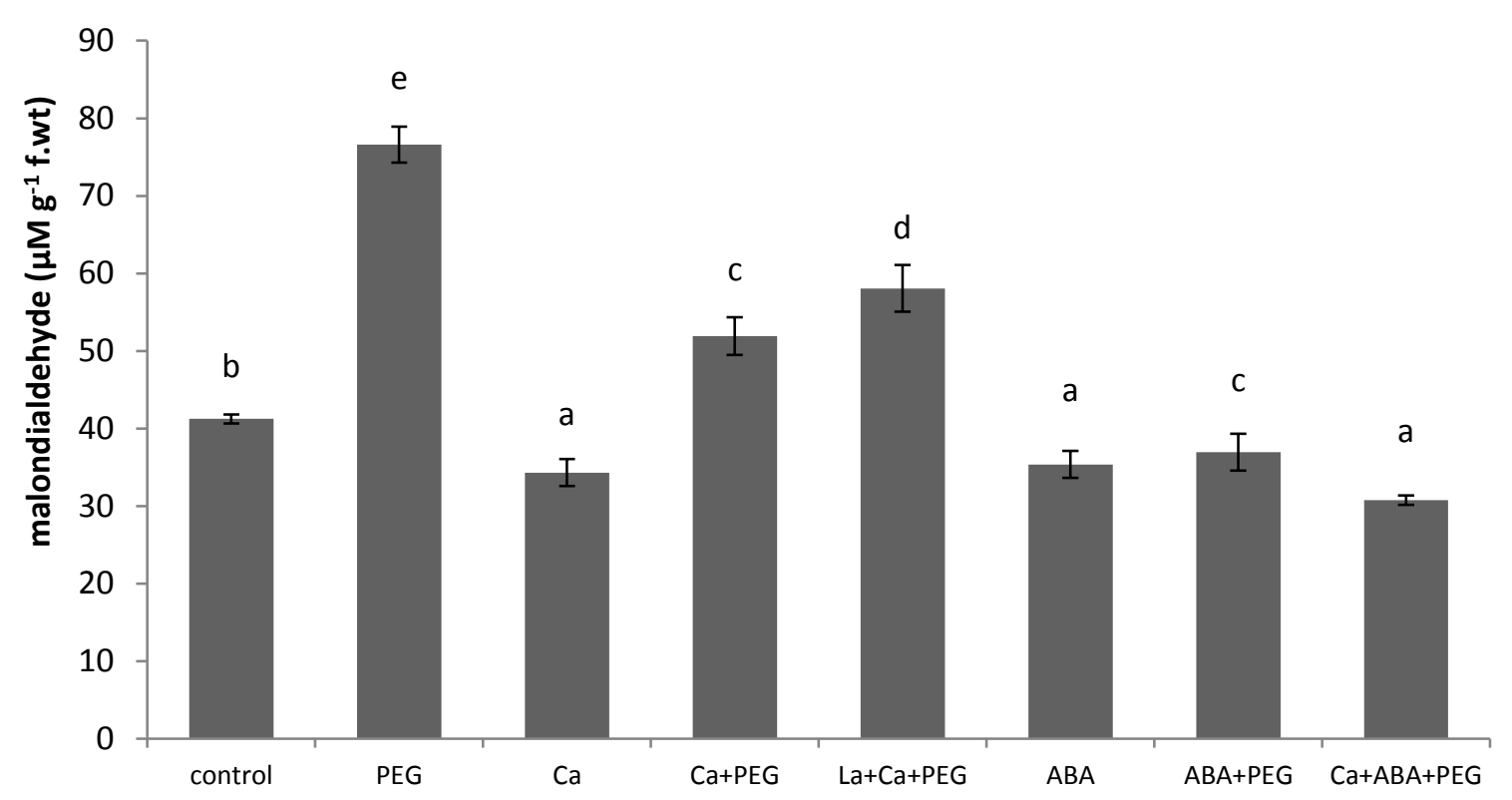

Fig. 4. The changes in malondialdehyde (MDA) content of $20 \%$ PEG-treated 14-day old T. aestivum seedlings with or without a pretreatment of $\mathrm{LaCl}_{3}(5 \mathrm{mM}), \mathrm{CaCl}_{2}(10 \mathrm{mM})$ and/or $\mathrm{ABA}(0.1 \mathrm{mM})$. Three biological replicates per treatment were used. Error bars represent standard deviations. Different letters indicate statistically significant $(\mathbf{P}<0.01)$ differences.

One way ANOVA analysis $(\mathrm{P}<0.01)$

$\begin{array}{lccc}\text { Parameters } & \text { LSD } & \text { F } & \text { Significance } \\ \text { Malondialdehyde content } & 3.86 & 144.27 & * *\end{array}$

** Highly significant

\section{Catalase activity}

As shown in Fig. 5, the activity of catalase was significantly increased with PEG treatment by $80 \%$, compared with the control. The treatments of $\mathrm{Ca}^{2+}$ and $\mathrm{ABA}$ either singly or combined with PEG, as well as their combinations, led to a highly significant recovery as the catalase activity was decreased relative to the PEG treatment but still higher than that of the control. The combined treatment of $\mathrm{La}^{3+}, \mathrm{Ca}^{2+}$ and PEG didn't induce any significant effect on catalase activity when compared with the PEG treatment, but its activity increased significantly compared with the combined treatment of $\mathrm{Ca}^{2+}$ and PEG indicating the role of $\mathrm{La}^{3+}$ as a calcium channel blocker.

\section{Ascorbic acid content}

As shown in Fig. 6, there was a remarkable increase in ascorbic acid content by $42.3 \%$ under the PEG application compared with the control. It was noticeable that the combined treatments of either $\mathrm{Ca}^{2+}$ or $\mathrm{ABA}$, or both of them, with PEG led to a significant decrease in ascorbic acid content compared with the PEG treatment indicating a recovery from the harmful effects imposed by PEG.

The ABA treatment resulted in a significant increase in the ascorbic acid content relative to the control, but the single $\mathrm{Ca}^{2+}$ treatment had no significant change when compared with the control. Moreover, a highly significant increase in ascorbic acid content was achieved under the combined treatments of $\mathrm{La}^{3+}, \mathrm{Ca}^{2+}$ and PEG as the ascorbic acid content was increased relative to the combined treatment of $\mathrm{Ca}^{2+}$ and $\mathrm{PEG}$, this increase indicates the role of $\mathrm{La}^{3+}$ in $\mathrm{Ca}^{2+}$ channel blocking (Fig. 6). 


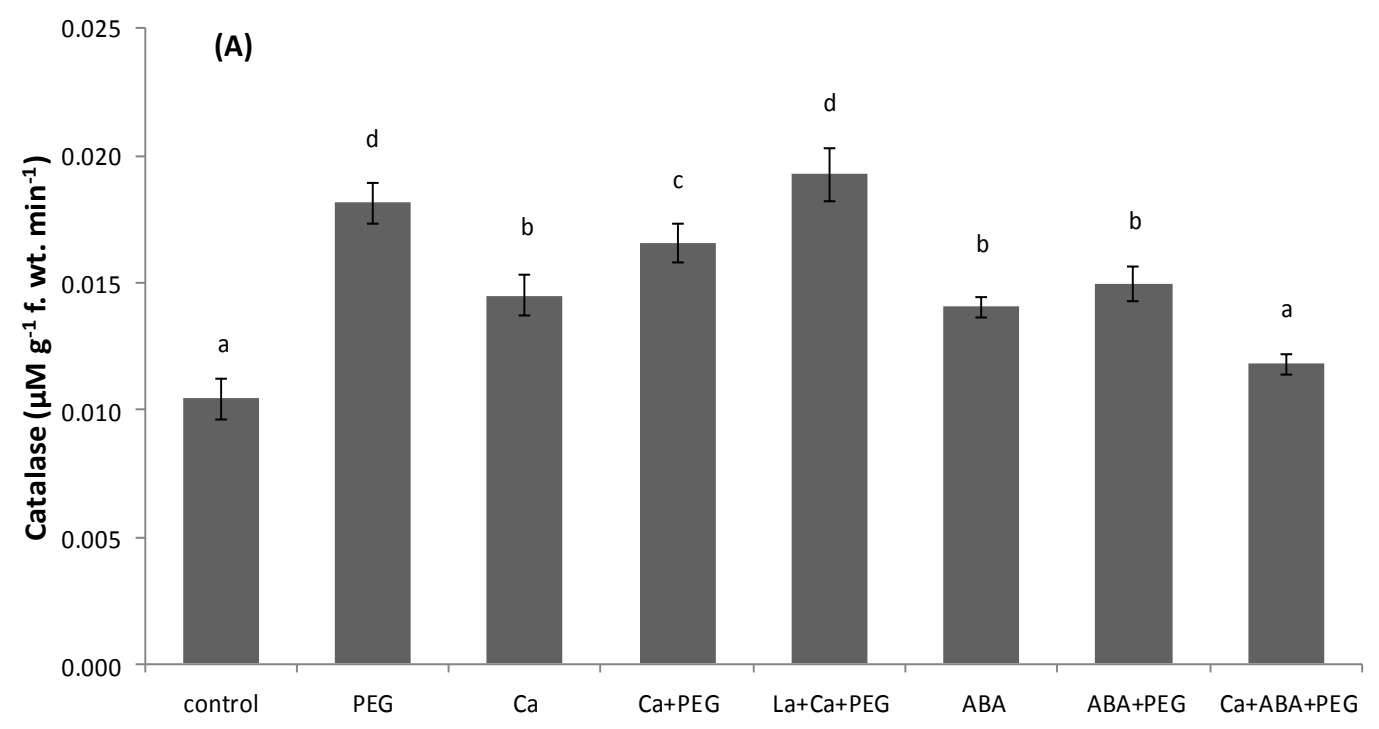

Fig. 5. The changes in catalase activity of $20 \%$ PEG-treated 14-day old $T$. aestivum seedlings with or without a pretreatment of $\mathrm{LaCl}_{3}(5 \mathrm{mM}), \mathrm{CaCl}_{2}(10 \mathrm{mM})$ and/or $\mathrm{ABA}(0.1 \mathrm{mM})$. Three biological replicates per treatment were used. Error bars represent standard deviations. Different letters indicate statistically significant $(\mathrm{P}<0.01)$ differences.

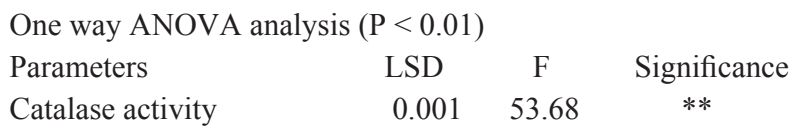

** Highly significant.

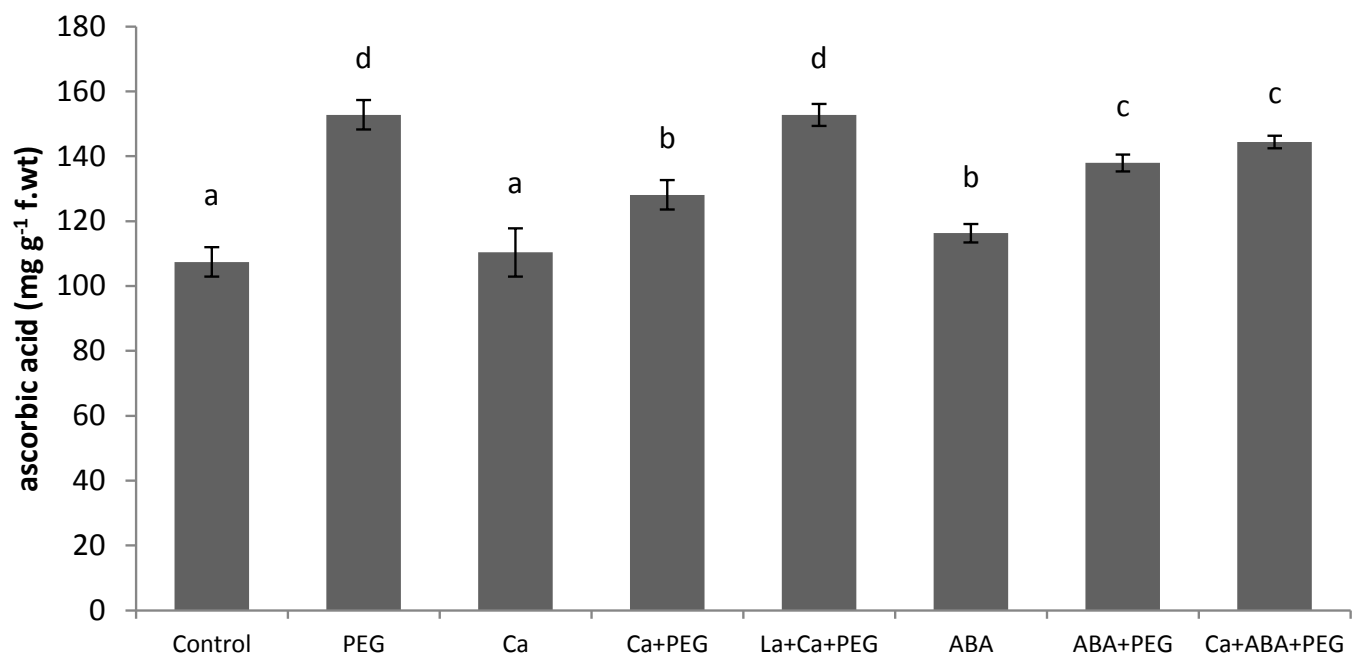

Fig. 6. The changes in ascorbic acid content of $20 \%$ PEG-treated 14-day old T. aestivum seedlings with or without a pretreatment of $\mathrm{LaCl}_{3}(5 \mathrm{mM}), \mathrm{CaCl}_{2}(10 \mathrm{mM})$ and/or $\mathrm{ABA}(0.1 \mathrm{mM})$. Three biological replicates per treatment were used. Error bars represent standard deviations. Different letters indicate statistically significant $(\mathrm{P}<0.01)$ differences.

One way ANOVA analysis $(\mathrm{P}<0.01)$

$\begin{array}{llcc}\text { Parameters } & \text { LSD } & \text { F } & \text { Significance } \\ \text { Ascorbic acid content } & 6.9 & 57.6 & * *\end{array}$

** Highly significant. 


\section{Endogenous ABA level}

Abscisic acid is well known to play a crucial signaling role during drought stress, and its induced synthesis under drought is well documented. The results presented in Fig. 7 revealed that PEG treatment led to a highly significant increase in the endogenous ABA level, this increase reached $93 \%$ compared with the control. It was also noticeable that $\mathrm{Ca}^{2+}$ treatment resulted in a highly significant increase in ABA content relative to the PEG treatment, as well as to the control. The increase of ABA content under $\mathrm{Ca}^{2+}$ treatment compared to control and PEG was $194 \%$ and $45.7 \%$, respectively. Additionally, the combined treatment of $\mathrm{La}^{3+}, \mathrm{Ca}^{2+}$ and PEG has caused a highly significant decrease in the endogenous ABA level relative to the control.

\section{Yield parameters}

The results presented here showed that the yield estimated parameters including the number of grains per spike and weight of 1000 grain were decreased under the PEG treatment by $24.4 \%$ and $19.6 \%$, respectively, compared to the control (Table 1). While, the combined treatment of $\mathrm{Ca}^{2+}$ and PEG led to a highly significant increase in these parameters. Noticeably, the combined treatment of $\mathrm{La}^{3+}, \mathrm{Ca}^{2+}$ and PEG resulted in a highly significant decrease in both of these yield parameters when compared with the combined treatment of $\mathrm{Ca}^{2+}$ and PEG.

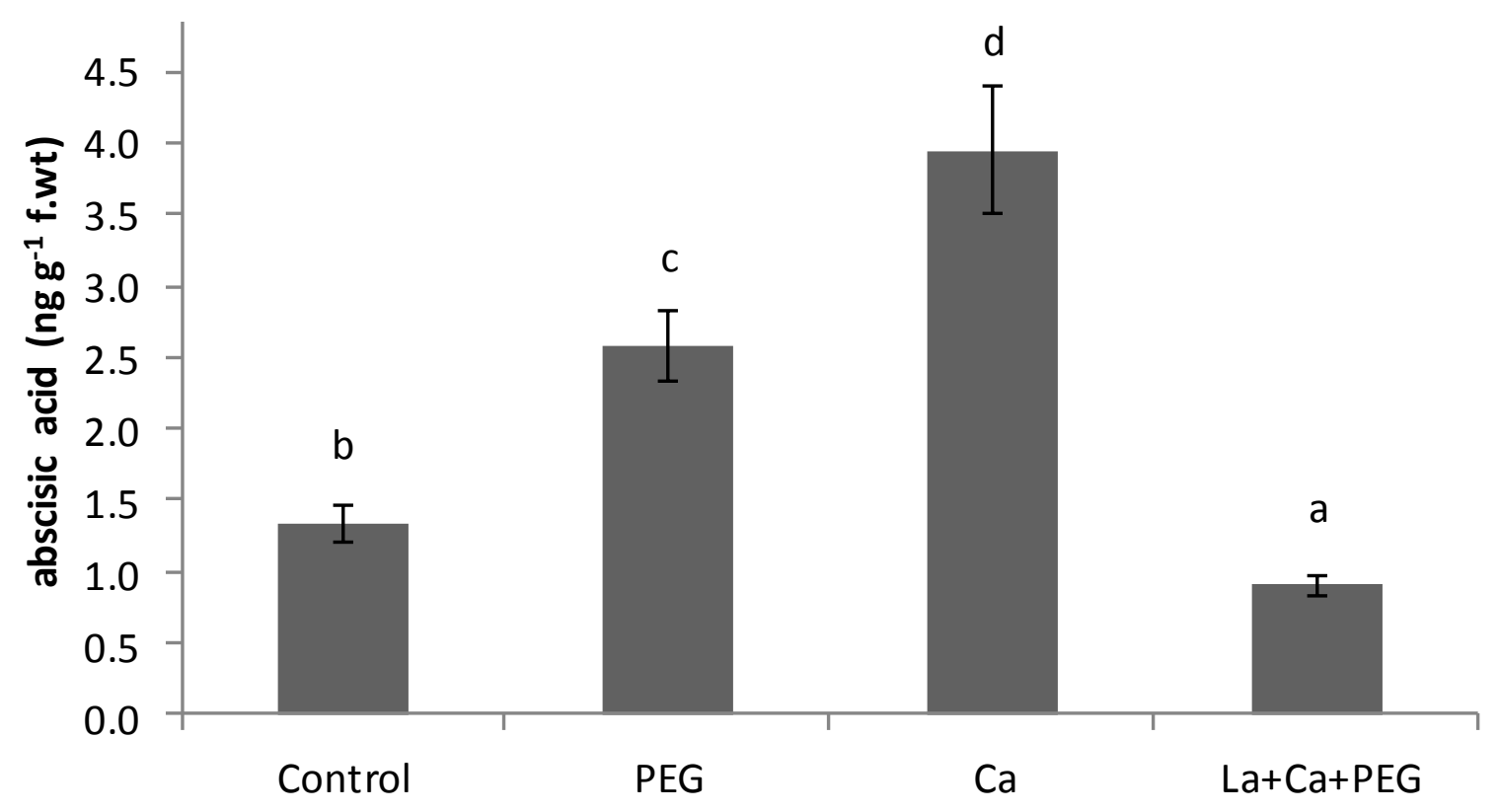

Fig. 7.The changes in the endogenous ABA level of $20 \%$ PEG-treated 14-day old T. aestivum seedlings under the influence of $\mathrm{CaCl}_{2}(10 \mathrm{mM})$ alone or preceded by $\mathrm{LaCl}_{3}(5 \mathrm{mM})$. Three biological replicates per treatment were used. Error bars represent standard deviations. Different letters indicate statistically significant $(\mathbf{P}<\mathbf{0 . 0 1})$ differences.

$\begin{array}{lccc}\text { One way ANOVA analysis }(\mathrm{P}<0.01) & & \\ \text { Parameters } & \text { LSD } & \mathrm{F} & \text { Significance } \\ \text { ABA content } & 0.42 & 81.35 & * *\end{array}$

** Highly significant. 
TABLE 1. The effect of $20 \%$ PEG with or without a pretreatment of $\mathrm{CaCl}_{2}(10 \mathrm{mM})$ and $\mathrm{LaCl}_{3}(5 \mathrm{mM})$ on yield parameters including the number (No.) of grains per spike and weight of 1000 grains of the T. aestivum plants. The yield parameters were measured in mature plants (about 120-day old). Three biological replicates per treatment were used.

\begin{tabular}{lcc}
\hline Treatments & No. of grains /spike & wt. of 1000 grain \\
\hline Control & $13.67 \pm 1.15$ & $16.30 \pm 0.27$ \\
PEG & $10.33 \pm 0.58$ & $13.10 \pm 0.36$ \\
$\mathrm{Ca}$ & $16.33 \pm 1.15$ & $20.97 \pm 1.07$ \\
$\mathrm{Ca}+\mathrm{PEG}$ & $12.00 \pm 1.00$ & $15.53 \pm 0.451$ \\
$\mathrm{La}+\mathrm{Ca}+\mathrm{PEG}$ & $11.00 \pm 1.00$ & $13.53 \pm 0.451$ \\
\hline
\end{tabular}

\begin{tabular}{lccc}
\multicolumn{2}{l}{ One way ANOVA analysis $(\mathrm{P}<0.01)$} & & \\
Parameters & LSD & $\mathrm{F}$ & Significance \\
No. of grains /spike & 1.82 & 17.33 & $* *$ \\
wt. of 1000 grain & 1.08 & 84.44 & $* *$
\end{tabular}

** Highly significant.

\section{Discussion}

Calcium improves the growth and alleviates the negative effects of drought stress on growth of wheat seedlings

Drought is one of the main abiotic stresses which adversely affects crop growth and yield (Zou et al., 2015). In the present study, drought stress (applied as PEG, 20\%) resulted in a significant reduction in shoot fresh and dry weights of Triticum aestivum seedlings (Fig. 2). These results were consistent with those reported by Riaz et al. (2010) on Turf grass, where water deficit conditions led to a significant inhibitory effect on shoot fresh and dry weights. The reduction in the monitored growth parameters may be attributed to that the reduction in soil moisture reduces the availability of nutrients to the plant and consequently reduce the growth (Razmjoo et al., 2008), in addition to the disturbance in cell physiology which may be associated with a decline in cell enlargement under water stress via low turgor pressure (Abdul, 2009 and Khayatnezhad et al., 2010).

Interestingly, results presented in this study showed that PEG (20\%) induced a highly significant increase in root fresh and dry weights of wheat seedlings (Fig. 2). Similarly, it was reported that drought-stressed cotton seedlings showed a relevant increase in root length (Pace et al., 1999). The increase in root growth may be due to the capability of a prolific root system to support the accelerated plant growth during the early crop growth stage. The reason may be, also, due to the less sensitivity of root growth than that of shoot to the same low levels of water potential (Hsiao \& Xu, 2000).
The present study revealed that $T$. aestivum seedlings treated with $10 \mathrm{mM} \mathrm{Ca}^{2+}$ had increased shoot fresh weight (Fig. 2). In this regared, it was reported that calcium deficiency reduce leaf growth, causing internode shortening near the apical bud, induce weak and malformed stems, as well as, necrosis (Stromme et al., 1994). Calcium was suggested to affect plant growth due to its role in mitosis and cytokinesis (Marschner, 1995). Our results reported that the lanthanum chloride $\left(\mathrm{LaCl}_{3}\right)$ has encountered the alleviating effects of $\mathrm{Ca}^{2+}$ on the inhibited growth of wheat seedlings caused by PEG. $\mathrm{La}^{3+}$ is known to reduce the magnitude of the $\mathrm{Ca}^{2+}$ elevation in response to drought stress caused by mannitol or salt stress treatments (Knight et al., 1996).

Data presented herein revealed that treating $T$. aestivum seedlings with $0.1 \mathrm{mM}$ ABA didn't show considerable effects on growth criteria as fresh and dry weights of shoot (Fig. 2). This finding may be attributed to that the effects of ABA may be occurred at molecular level that wasn't clearly reflected in the growth criteria.

Calcium and ABA alleviate the inhibiting effects of drought stress on photosynthetic activity in wheat seedlings

Parallel to the inhibitory effects of PEG on growth, there was a highly significant decrease in the photosynthetic efficiency under PEG treatment (Fig. 3). In accordance with these findings, it was reported that drought stress led to a decrease in the $\mathrm{Fv} / \mathrm{Fm}$ ratio in bean plant, 
suggesting chronic photo-inhibition due to photooxidation of photosynthetic apparatus (Sewelam et al., 2014) and damage to the PSII oxygenevolving complex possibly attributable to D1 protein damage under drought stress (Zlatve \& Yordanov, 2004). Likewise, it was suggested that the photosynthetic efficiency has been declined in Nothofagus species under drought stress (Piper et al., 2007 and Luo et al., 2015). Similar effects on chlorophyll fluorescence parameters under drought stress have been observed in different species, among them Brassica napus (Kauser et al., 2006) and Aegilops species (Dulai et al., 2006).

$\mathrm{Ca}^{2+}$ is well documented to improve photosynthetic efficiency under drought stress. In a study carried out on Zoysia japonica, Chengbin et al. (2013) reported that the Fv/Fm ratio was higher in plants pretreated with $10 \mathrm{mM}$ $\mathrm{CaCl}_{2}$, and this is in agreement with our results (Fig. 3). Where $\mathrm{Ca}^{2+}$ treatment has increased the $\mathrm{Fv} / \mathrm{Fm}$ and also alleviated the decrease in Fv/ Fm caused by PEG treatment. This action of $\mathrm{Ca}^{2+}$ was confirmed through pretreating wheat seedlings with the calcium channel blocker $\mathrm{LaCl}_{3}$, which has abolished the effects of $\mathrm{Ca}^{2+}$ (Fig. 3). These findings may be attributed to the requirement of $\mathrm{Ca}^{2+}$ as a co-factor in PSII for the oxygen evolving system (Miqyass et al., 2007). Calcium has also been shown to be essential for photo-assembly of PSII manganese clusters by preventing photo-inactivation (Chen et al., 1995).

ABA treatments led to a highly significant increase in Fv/Fm (Fig. 3), which may be attributed to the role of ABA in suppressing the increases in electrolyte leakage (Rajasekaran \& Blake, 1999 and Sewelam et al., 2017), suggesting that ABA could reduce drought injury by protecting cell membranes and photosynthetic apparatus. The reported synthesis of dehydrin proteins under ABA treatment may represent another protective process induced by ABA (Landi et al., 2001).

Drought causes oxidative stress and affects the cell antioxidant activities, while $\mathrm{Ca}^{+}$and $\mathrm{ABA}$ alleviate these effects

Drought as well as almost all abiotic stresses induce the accumulation of ROS leading to an oxidative cell damage (Luo et al., 2015), especially the oxidation of lipids in cell membranes. Results of the present study showed a highly significant increase in lipid peroxidation levels (measured as MDA content) under PEG treatment (Fig. 4). It was reported that the level of lipid peroxidation (MDA content) increased with increasing the magnitude of the drought stress (Harish et al., 2010).

Interestingly, the present study suggested that $\mathrm{Ca}^{2+}$ pretreatment decreased the level of MDA in the drought treated seedlings (Fig. 4). This decrease in MDA content indicates the alleviating role of $\mathrm{Ca}^{2+}$ in decreasing the deleterious effects imposed by PEG. Exogenous $\mathrm{Ca}^{2+}$ can enhance plant drought resistance, and protect the structure of cellular membranes thus regulating the physiological responses induced by drought stress (Tuberosa et al., 2007). Results of the present work showed that the pretreatment of $\mathrm{La}^{3+}$ has abolished the $\mathrm{Ca}^{2+}$ alleviating effects on drought stressed T. aestivum seedlings leading to high peroxidation levels (Fig. 4). Regarding ABA, data presented herein showed that $\mathrm{ABA}$ decreased the MDA content. It was found that $\mathrm{ABA}$ is involved in membrane stability which may be achieved through ABA involvement in lipid metabolism (Zou et al., 1995). ABA may also alleviate the effect of PEG on plant as ABA interacts with membrane phospholipids to stabilize the membranes under stress conditions (Guschina et al., 2002).

Plants have developed antioxidant defense mechanisms to scavenge the free radicals and peroxides to alleviate their damaging effects. These include various enzymatic antioxidants such as catalases (CAT), and peroxidases (POX), in addition to other endogenous antioxidant compounds such as ascorbic acid (ASA) and glutathione (Li et al., 2012). CAT represents an efficient antioxidant enzyme that does not require a reductant for catalyzing dismutation reactions (Adriano et al., 2015). Our results indicated that PEG treatment has significantly increased the activity of CAT (Fig. 5). It was reported that CAT activity in Avena species were increased significantly with increasing the levels of water stress (Harish et al., 2010). The increase in the activity of CAT was correlated with the recorded increase of MDA content under PEG treatment.

The combined treatment of $\mathrm{Ca}^{2+}$ and PEG led to a highly significant reduction in the activity of catalase when compared with PEG treatment (Fig. 5). This reduction may be attributed to the role of $\mathrm{Ca}^{2+}$ in alleviating the damaging effects of drought 
through its inhibiting role in the production of activating oxides (Tuberosa et al., 2007), as well as, its role in sustaining the membrane integrity (Lu et al., 1993). This role of $\mathrm{Ca}^{2+}$ may increase the cell adaptation and relief, and thus decrease the activity of catalase where there is no much ROS. On the other hand, the combined treatment of ABA and PEG resulted in a highly significant reduction in CAT activity (Fig. 5). This finding may be attributed to the role of ABA in stomatal closure and reducing water transpiration (Kim et al., 2010), as well as the role of ABA in increasing $\mathrm{K}^{+}$ion during oxidative stress which help in maintaining the membranes integrity (Hatata et al., 2009), and hence reducing oxidative stress. The combined pretreatment of both $\mathrm{Ca}^{2+}$ and ABA had synergistic relief effects resulting in a highly significant reduction in CAT activity under drought stress (Fig. 5).

The non-enzymatic antioxidant compound ascorbic acid (ASA) is involved in the cellular scavenging system controlling ROS. ASA represents the major water-soluble antioxidant in plant leaves, it can provide protection to membranes by directly scavenging the $\mathrm{O}_{2}, \mathrm{OH}$ and regenerating $\alpha$-tocopherol from tocopheroxyl radical (Smirnoff, 2005). Data presented here showed that the PEG treatments led to increasing the ASA content in the treated seedlings indicating an active stress adaptation (Fig. 6). A marked increase of ASA was recorded under drought in rice, apple trees and mulberry (Reddy et al., 2004 and Abogadallah, 2010.). The increase in CAT activity and ASA content reported in our study under drought stress conditions, with other expected defense responses, may represent a tolerance energy cost that contribute for the reduction in plant growth during water regimes (Fig. 2).

ABA combined treatment with PEG led to an evident decrease in ASA content when compared with PEG treatment (Fig. 6). This result may be due to that ABA play an important role in the enhancement of tolerance to oxidative stress (Jiang \& Zhang, 2001, 2004 and Yoshida et al., 2003).

Calcium works upstream from ABA in certain pathways activated by drought stress

It is well documented that ABA acts as a stress signal, which triggers adaptive changes in physiology and morphology of plants (Lim et al., 2015). The present data revealed that PEG treatment induced an increase in endogenous ABA level (Fig. 7). Similar increases of ABA level were observed in Arabidopsis thaliana under osmotic stress (Ozfidan et al., 2012), as well as in wheat leaves under soil drought stress (Guoth et al., 2009). These findings may be attributed to the controlling role of $\mathrm{ABA}$ on the expression of a large set of stress-responsive genes. ABA treatment induces changes in gene expression in more than $10 \%$ of the Arabidopsis genome (Zeller et al., 2009), resulting in the increased expression of stress associated and signaling component transcripts (Yamaguchi-Shinozaki \& Shinozaki, 2005). The increase in ABA content under drought or salinity stress conditions stimulates stomatal closure and the accumulation of osmo-compatible solutes, thus increasing the plant's capacity to cope with stress conditions (Seki et al., 2007 and Daszkowska-Golec \& Szarejko, 2013).

As a second messenger, calcium connects the perception of different stimuli and stresses to their downstream cellular responses (Evans et al., 2005 and Dubiella et al., 2013). To check whether $\mathrm{Ca}^{2+}$ is working upstream or downstream from the plant hormone ABA during drought stress, the endogenous ABA levels were measured under different treatments. Our data showed that $\mathrm{Ca}^{2+}$ treatment has increased the endogenous ABA level exceeding the control and PEG values (Fig. 7). The results, also, showed that using $\mathrm{La}^{3+}$ preceding the addition of $\mathrm{Ca}^{2+}$ decreased the endogenous ABA level significantly. Furthermore, the level of the endogenous ABA under $\mathrm{La}^{3+}$ pretreatment was lower than its level under control and PEG treatment (Fig. 7) indicating that the increase of ABA under drought stress would be mediated by an endogenous increase in $\mathrm{Ca}^{2+}$. This conclusion suggests that $\mathrm{Ca}^{2+}$ is working upstream from $\mathrm{ABA}$ that is induced by drought treatment in wheat seedlings. $\mathrm{Ca}^{2+}$ was found to participate in the process of $\mathrm{ABA}$-induced drought signal transferring under PEG stress, where ABA synthesis was related with cytoplasmic $\mathrm{Ca}^{2+}$ concentrations (Noctor, 2006 and Scherzer et al., 2012).

However, the combined treatment of $\mathrm{Ca}^{2+}$ and ABA with PEG did not show synergistic effects regarding the alleviation of drought stress (Fig. 2 and 3). This may suggest that both, $\mathrm{Ca}^{2+}$ and $\mathrm{ABA}$, may use identical signaling pathways with $\mathrm{Ca}^{2+}$ working upstream from $\mathrm{ABA}$ only in some of the many pathways activated by $\mathrm{Ca}^{2+}$ (Fig. 8). 


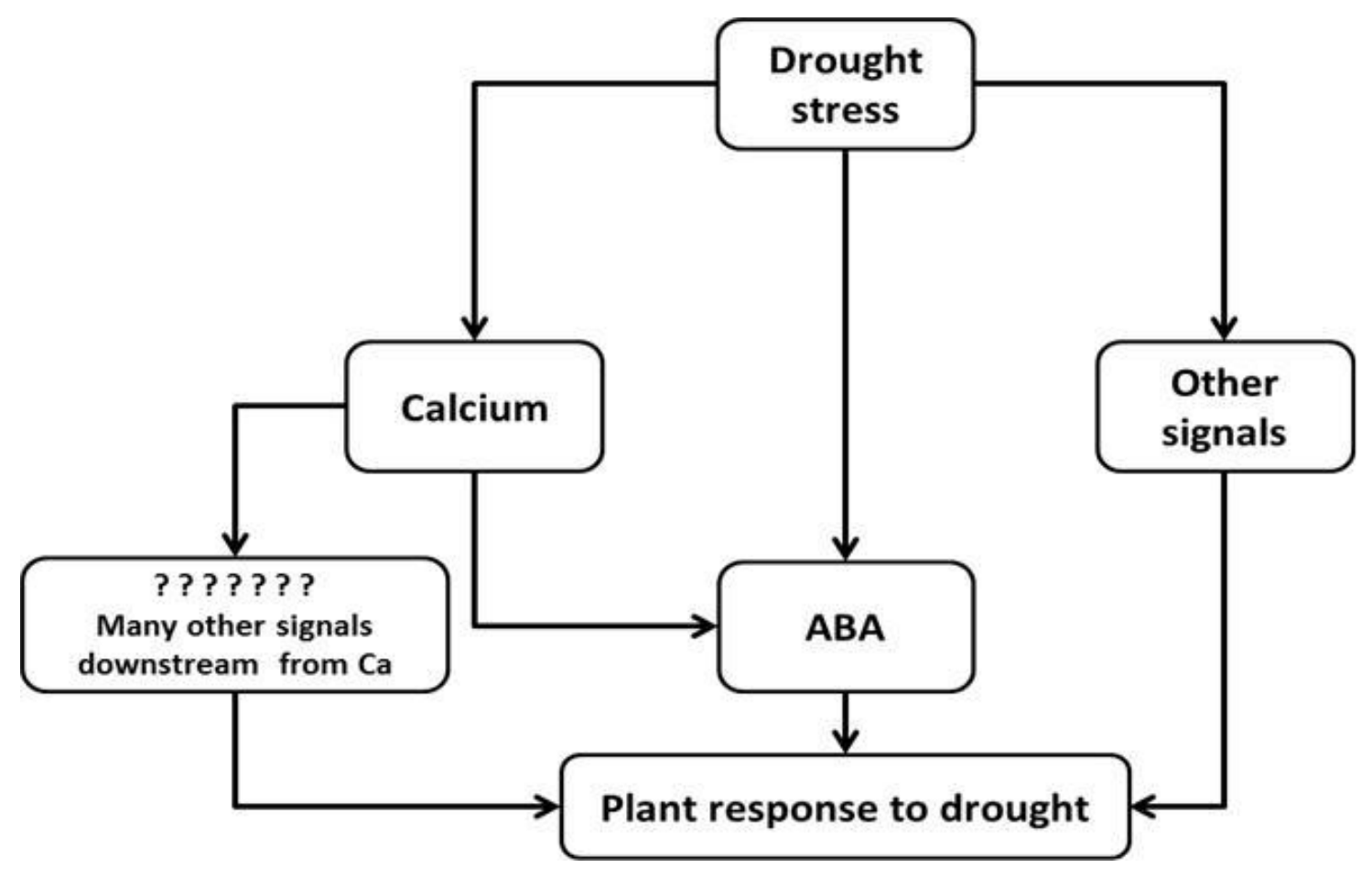

Fig. 8. A scheme presenting the expected interactions between calcium and ABA under drought stress.

The effects of drought and $\mathrm{Ca}^{+}$treatments are prolonged to the yield stage

PEG application led to a marked decrease in yield parameters including the number of grains per spike and weight of 1000 grain (Table 1). It was reported that, the spike length, number of grains per spike and weight of 1000 grain weight were significantly decreased in drought stressed wheat plants (Bano et al., 2012). It was reported that the deficiency of water causes decline in yield traits of crop plants probably by disrupting leaf gas exchange which limits the assimilate translocation and dry matter partitioning (Farooq et al., 2009). Also, the disturbed nutrient uptake efficiency that frequently occurs during drought stress could lead to yield reduction (Riaz \& Chowdhry, 2003). The present work showed that when wheat plants were pretreated with $\mathrm{Ca}^{2+}$, they produced higher yield compared to the PEG-treated ones (Table 1). These findings suggest that the alleviating effect of $\mathrm{Ca}^{2+}$ to drought stress is prolonged to the yield stage.

\section{Conclusion}

The work presented in this study showed that drought stress imposed by treating wheat seedlings with polyethylene glycol (PEG, 20\%) has led to a significant reduction in growth of wheat seedlings. In addition, PEG inhibited the photosynthetic activity and led to oxidative stress where it has increased the level of lipid peroxidation. Higher activities of the antioxidant enzyme catalase, together with an elevation of the antioxidant compound ascorbic acid, were recorded with the PEG treatment. Pretreating wheat seedlings with calcium chloride $\left(\mathrm{Ca}^{2+}\right.$, $10 \mathrm{mM}$ ) or abscisic acid (ABA, $0.1 \mathrm{mM}$ ) led to alleviating the above mentioned damaging effects of PEG, but the effects of calcium were more pronounced compared to that of the ABA. The use of lanthanum chloride $\left(\mathrm{LaCl}_{3}\right.$, a calcium channel blocker) has confirmed the role of $\mathrm{Ca}^{2+}$ in ameliorating the drought effects on the plant. PEG treatment resulted in a significant increase in the endogenous ABA level of the treated seedlings. Interestingly, the application of $\mathrm{Ca}^{2+}$ increased endogenous ABA level of treated seedlings to a high extent exceeding that of PEG treatment itself suggesting that $\mathrm{ABA}$ requires $\mathrm{Ca}^{2+}$ ions for its induction, and $\mathrm{ABA}$ is working downstream of $\mathrm{Ca}^{2+}$. On the whole, the results presented here suggested that $\mathrm{Ca}^{2+}(10 \mathrm{mM})$ represents an effective agent for alleviating drought stress in plants growing in environments suffering from drought stress. 


\section{References}

Abdul, K.K.A. (2009) Effect of water stress on imbibition, germination and seedling growth of maize cultivars. Sar. J. Agri. 25(2), 165-172.

Abogadallah, G.M. (2010) Antioxidative defense under salt stress. Plant Signal Behav. 5(4), 369-374.

Adriano, S., Antonio, S., Maria, N. and Antonella, V. (2015) Ascorbate peroxidase and catalase activities and their genetic regulation in plants subjected to drought and salinity stresses. Int. J. Mol. Sci. 13561-13578.

An, Y., Liu, L., Chen, L. and Wang, L. (2016) ALA inhibits ABA-induced stomatal closure via reducing $\mathrm{H}_{2} \mathrm{O}_{2}$ and $\mathrm{Ca}^{2+}$ levels in guard cells. Front. Plant Sci. 11(7), 482 .

Anjum, S.A., Xie, X., Wang, L., Saleem, M.F., Man, C. and Lei, W. (2011) Morphological, physiological and biochemical responses of plants to drought stress. Afri. J. Agri. Res. 6, 2026-2032.

Bano, F., Ullah, A. and Nosheen, S. (2012) Role of abscisic acid and drought stress on the activities of antioxidant enzymes in wheat. Plant Soil Environ. 8(4), 181-185.

Bari, R. and Jones, J.D.G. (2009) Roles of plant hormones in plant defense responses. Plant Mol. Biol. 69, 473-488.

Beauchamp, C. and Fridovich, I. (1971) Superoxide dismutase, improved assays and an assay applicable to acrylamide gels. Anal. Biochem. 44, 276-287.

Chen, C., Kazimir, J. and Cheniae, G.M. (1995) Calcium modulates the photoassembly of photosystem II (Mn)4-clusters by preventing ligation of nonfunctional high-valency states of manganese. Biochem. 43(41), 13511-13526.

Chengbin, X., Li, X.and Zhang, L. (2013) The effect of calcium chloride on growth, photosynthesis and antioxidant responses of Zoysia japonica under drought conditions. PLoS ONE, 8, e68214.

Daszkowska-Golec, A. and Szarejko, I. (2013) Open or close the gate - stomata action under the control of phytohormones in drought stress conditions. Front. Plant Sci. 4, 138.

Davies, W.J., Wilkinson, S. and Loveys, B.R. (2002) Stomatal control by chemical signaling and the exploitation of this mechanism to increase water use efficiency in agriculture. New Phytol. 153, 449-460.

Dubiella, U, Seybold, H., Durian, G., Komander, E., Lassig, R., Witte, C.P., Schulze, W.X. and Romeis,
T. (2013) Calcium dependent protein kinase/ NADPH oxidase activation circuit is required for rapid defense signal propagation. Proc. Natl. Acad. Sci. USA, 110, 8744-8749.

Dulai, S., Molnar, I., Pronay, J., Csernak, A., Tarnai, R. and Molnarlang, M. (2006) Effects of drought on photosynthetic parameters and heat stability of PSII in wheat and in Aegilops species originating from dry habitats. Acta Biol. Szegediensis, 50, 11-17.

Emmerich, W.E. and Hardegree, S.P. (1990) Polyethylene glycol solution contact effects on seed germination, Agron J. 82, 1103-1107.

Evans, N.H., McAinsh, M.R., Hetherington, A.M. and Knight, M.R. (2005) ROS perception in Arabidopsis thaliana: the ozone induced calcium response. Plant J. 41, 615-626.

Farooq, M., Wahid ,A., Kobayashi, N., Fujita, D. and Basra, S.M.A. (2009) Plant drought stress: effects, mechanisms and management. Agron. Sustain. Dev. 29, 185-212.

Foyer, C.H. and Noctor, G. (2003) Redox sensing and signaling associated with reactive oxygen in chloroplasts, peroxisomes and mitochondria. Physiol. Plant, 119, 355-364.

Francisco, J.C. and Juan, B.B. (2014) Peroxisomal plant nitric oxide synthase (NOS) protein is imported by peroxisomal targeting signal type 2 (PTS2) in a process that depends on the cytosolic receptor PEX7 and calmodulin. F.J. Corpas, J.B. Barroso / FEBS Letters, 588, 2049-2054.

Fujita, M., Fujita, Y., Noutoshi, Y., Takahashi, F., Narusaka, Y., Yamaguchi -shinozaki, K. and Shinozaki, K. (2006) Crosstalk between abiotic and biotic stress responses: a current view from the points of convergence in the stress signaling networks. Curr. Opin. Plant Biol. 9, 436-442.

Gilroy, S., Białasek, M., Suzuki, N., Górecka, M., Devireddy, A.R., Karpiński, S. and Mittler, R. (2016) ROS, calcium and electric signals: Key mediators of rapid systemic signaling in plants. Plant Physiol. 171(3), 1606-15.

Giuliani, S., Sanguineti, M.C., Tuberosa, R., Bellotti, M., Salvi, S. and Landi, P. (2005) Root-ABA1 a major constitutive QTL affects maize root architecture and leaf $\mathrm{ABA}$ concentration at different water regimes. J. Exp. Bot. 56, 3061-3070

Gonçalves, J.F.C. and Santos Júnior, U.M. (2005) Utilization of the chlorophyll a fluorescence technique as a tool for selecting tolerant species to environments of high irradiance. Braz. J. Plant Physiol. 17, 307-313. 
Guoth, A., Tari, I., Galle, A., Csiszar, J., Pecsvaradi, A., Cseuz, L. and Erdei, L. (2009) Comparison of the drought stress responses of tolerant and sensitive wheat cultivars during grain filling: changes in flag leaf photosynthetic activity, ABA levels, and grain yield. J. Plant Growth Regul. 28, 167-176.

Guschina, I.A., Harwood, J.L., Smith, M. and Beckett, R.P. (2002) Abscisic acid modifies the changes in lipids brought about by water stress in the moss Atrichum androgynum. New Phytol. 156, 255-264.

Harish, C.P., Baig, M.J., Chandra, A. and Bhatt, R.K. (2010) Drought stress induced changes in lipid peroxidation and antioxidant system in genus Avena. J. Environ. Biol. 31, 435-440.

Hatata, M.M., Hala, M.T. and Dowidar, S.M. (2009) Phytohormones effect on growth and certain metabolic aspects of $\mathrm{NaCl}$ stressed Barley plant. Egypt J. Exp. Biol. (Bot.), 5, 149-155.

Heath, R.L. and Packer, L. (1968) Photoperoxidation in isolated chloroplasts. I. Kinetics and stoichiometry of fatty acid peroxidation. Arch. Biochem. Biophys. 125, $189-198$.

Hsiao, T. and Xu, L.K. (2000) Sensitivity of growth of roots versus leaves to water stress: biophysical analysis and relation to water transport. J. Exp. Bot. 51, 1595-1616.

Hussein, M., Kassab, O. and Ellil, A. (2008) Evaluating water stress influence on growth and photosynthetic pigments of two sugar beet varieties. Res. J. Agri. Biol. Sci. 4, 936-941.

Jiang, M. and Zhang, J. (2001) Effect of abscisic acid on active oxygen species, antioxidative defense system and oxidative damage in leaves of maize seedlings. Plant Cell Physiol. 42, 1265-1273.

Jiang, M. and Zhang, J. (2004) Abscisic acid and antioxidant defense in plant cells. Acta Botanica Sinica, 46, 1-9.

Kato, M. and Shimizu, S. (1987) Chlorophyll metabolism in higher plants. VII- chlorophyll degradation in senescing tobacco leaves; phenolic- dependent peroxidative degradation. Cand. J. Bot. 65, 729-735.

Kauser, R., Athar. H. and Ashraf, M. (2006) Chlorophyll fluorescence: a potential indicator for assessment of water stress tolerance in canola (Brassica napus L.). Pakistan J. Bot. 38(5), 1501-1509.

Khayatnezhad, M., Gholamin, R., Jamaati, E., Somarin, S.H. and Zabihi-Mahmoodabad, R. (2010) Effects of PEG stress on corn cultivars (Zea mays L.) at germination stage. World Applied Scientific J. 11, 504506.
Kim, T.H., Bohmer, M., Hu, H., Nishimura, N. and Schroeder, J.I. (2010) Guard cell signal transduction network: advances in understanding abscisic acid, $\mathrm{CO}_{2}$, and $\mathrm{Ca}^{2+}$ signaling. Annu. Rev. Plant Biol. 61, 561-591.

Knight, H., Trewavas, A.J. and Knight, M.R. (1996) Cold calcium signaling in Arabidopsis involves two cellular pools and a change in calcium signature after acclimation. Plant Cell, 8, 489-503.

Landi, P., Sanguineti, M.C., Conti, S. and Tuberos, R. (2001) Direct and correlated responses to divergent selection for leaf abscisic acid concentration in two maize populations. Crop Sci.,41, 335-344.

Larher, F., Leport, L., Petrivalsky, M. and Chappart, M. (1993) Effectors for the osmoinduced praline response in higher plants. Plant Physiol. Biochem. 31(6), 911922.

Lee, S.C., Lim, C.W., Lan, W., He, K. and Luan, S. (2013) ABA signaling in guard cells entails a dynamic proteinprotein interaction relay from the PYL-RCAR family receptors to ion channels. Mol. Plant. 6, 528-538.

Li, X., Bu, N., Li, Y., Ma, L., Xin, S. and Zhang, L. (2012) Growth, photosynthesis and antioxidant responses of endophyte infected and non-infected rice under lead stress conditions. J. Hazard. Mater. 213, $55-61$.

Lim, C.W., Baek, W., Jung, J., Kim, J.H. and Lee, S.C. (2015) Function of ABA in stomatal defense against biotic and drought stresses. Int. J. Mol. Sci. 16(7), 15251-70.

Lu, S.Y., Li, Y.C., Guo, Z.F., Li, B.S. and Li, M.Q. (1993) Enhancement of drought resistance of rice seedlings by calcium. Chin J. Rice, 13, 161-164.

Luo, J., Tang, S., Peng, X., Yan, X., Zeng, X., Li, J., Li, X. and $\mathrm{Wu}, \mathrm{G}$. (2015) Elucidation of cross-talk and specificity of early response mechanisms to salt and PEG-simulated drought stresses in Brassica napus using comparative proteomic analysis. PLoS One, 10, e0138974.

Marschner, H. (1995) "Mineral Nutrition of Higher Plants". $2^{\text {nd }}$ ed. Academic Press. London, Great Britain. 889 p.

McSteen, P. and Zhao, Y. (2008) Plant hormones and signaling: common themes and new developments. Dev. Cell, 14, 467-473.

Miqyass, M., van Gorkom, H.J. and Yocum, C.F. (2007) The PSII calcium site revisited. Photosynth. Res. 92, 275-287.

Mittler, R. (2002) Oxidative stress, antioxidants, and stress tolerance. Trends Plant Sci. 9, 405-410. 
Noctor, G. (2006) Metabolic signaling in defense and stress: the central roles of soluble redox couples. Plant Cell Environ. 29, 409-25.

Oser, B.L. (1979) "Hawk's Physiological Chemistry". pp.702 - 705, Mc Graw Hill; NY; USA.

Ozfidan, C., Turkan, I., Sekmen, A.H. and Seckin, B. (2012) Abscisic acid-regulated responses of aba21 under osmotic stress: the abscisic acid-inducible antioxidant defense system and reactive oxygen species production. Plant Biol. 14, 337-346.

Pace, P.F., Cralle, H.T., El-Halawany, S.H.M., Cothren, J.T. and Senseman, S.A. (1999) Drought-induced changes in shoot and root growth of young cotton plants. J. Cotton Sci. 3, 183-187.

Piper, F., Corcuera, L., Alberdi, M. and Lusk, C. (2007) Differential photosynthetic and survival responses to soil Effects of drought stress on tolerant and sensitive chickpea genotypes 55 drought in two evergreen Nothofagus species. Ann. forest Sci. 64, $447-452$.

Rajasekaran, L.R. and Blake, T.J. (1999) New plant growth regulators protect photosynthesis and enhance growth under drought of jack pine seedlings. J. Plant Growth Regul. 18, 175-181.

Ravi, R.K., Krishna, K. and Naik, G.R. (2011) Effect of polyethylene glycol induced water stress on physiological and biochemical responses in Pigeonpea (Cajanus cajan L. Mill sp.). Recent Research in Science and Technology, 3, 148-152.

Razmjoo, K., Heydarizadeh, P. and Sabzalian, M.R. (2008) Effect of salinity and drought stresses on growth parameters and essential oil content of Matricaria chamomile. Int. J. Agri. Biol. 10, 451454.

Reddy, A.R., Chaitanya, V., Jutur, P.P. and Sumithra, K. (2004) Differential antioxidative responses to water stress among five mulberry (Morus alba L.) cultivars. Environ. Exp. Bot. 52(1), 33-42.

Riaz, R. and Chowdhrv, M. (2003) Genetic analysis of some economic traits of wheat under drought condition. Asian J. Plant Sci. 2, 790-796.

Riaz, A., Younis, A., Hameed, M. and Kiran, S. (2010) Morphological and biochemical responses of turf grasses to water deficit condition. Pak. J. Bot. 42, 3441-3448.

Sanders, D., Pelloux, J., Brownlee, C. and Harper, J.F. (2002) Calcium at the crossroads of signaling. Plant Cell, S401-S417.

Scherzer, S., Maierhofer, T., Al-Rasheid, K.A., Geiger,
D. and Hedrich, R. (2012) Multiple calciumdependent kinases modulate ABA-activated guard cell anion channels. Mol. Plant, 5, 1409-1412.

Seki, M., Umezawa, T., Urano, K. and Shinozaki, K. (2007) Regulatory metabolic networks in drought stress responses. Curr. Opin. Plant Biol. 10, 296302.

Sewelam, N., Jaspert, N., Kelen, K.V.D., Schmitz, J., Frerigmann, H., Tognetti, V.B., Stah, E., Zeier, J., Breusegem, F.V. and Maurino, V.G. (2014) Spatial $\mathrm{H}_{2} \mathrm{O}_{2}$ signalling specificity: $\mathrm{H}_{2} \mathrm{O}_{2}$ from chloroplasts and peroxisomes differentially modulates the plant transcriptome. Molecular Plant, 7(7), 1191-1210.

Sewelam, N., Kazan, K. and Schenk, P.M. (2016) Global plant stress signaling: reactive oxygen species at the cross-road. Front Plant Sci. 7, 187, doi: 10.3389/ fpls. 2016-00187.

Sewelam, N., Abo-Kassem, E.A., Sobhy, S. and Dowidar, S. (2017) Roles of calcium and ABA in alleviating drought stress effects on Triticum aestivum L. Plants. Eg. J. Exp. Biol. (Bot.), 13(2), $423-438$.

Shao, H.B., Chu, L.Y., Jaleel, C.A. and Zhao, C.X. (2008) Water deficit stress induced anatomical changes in higher plants. Comp. Rend. Biol. 331(3), 215-225.

Shindy, W.W. and Smith, E.O. (1975) Identification of plant hormones from cotton ovules. Plant Physiol. 550-554.

Smirnoff, N. (2005) Ascorbate, tocopherol and carotenoids: metabolism. Pathway engineering and functions. In: " Antioxidants and Reactive Oxygen Species in Plants" Smirnoff, N. (Ed.), pp.53-86. Oxford, Blackwell Publishing.

Steel, R.G.D. and Torrie, J.H. (1980) "Principles and Procedures of Statistics". $2^{\text {nd }}$ ed. New York: McGraw-Hill.

Stromme, E., Selmer-Olsen, A.R., Gislerød, H.R. and Moe, R. (1994) Cultivar differences in nutrient absorption and susceptibility to bract necrosis in poinsettia (Euphorbia pulcherrima Willd. ex Klotzsch). Gartenbauwissenschaft, 59, 6-12.

Taji, T., Iuchi, S., Kobayashi, M., Naramoto, M., Seki, M., Kato, T., Tabata, S., Kakubari, Y., YamaguchiShinozaki, K. and Shinozaki, K. (2001) Regulation of drought tolerance by gene manipulation of 9-cisepoxycarotenoid dioxygenase, a key enzyme in abscisic acid biosynthesis in Arabidopsis. Plant J. 325-33.

Tracy, K., Susan, E.F., Elizabeth, A.B. and Mary, A.O. 
(1993) Characterization of expression of droughtand abscisic acid regulated tomato genes in the drought-resistant species Lycopersicon penne. Plant Physiol. 103, 597-605.

Tuberosa, R., Giuliani, S., Parry, M.A.J. and Araus, J.L. (2007) Improving water use efficiency in Mediterranean agriculture: what limits the adoption of new technologies? Ann. Appl. Biol. 157-162.

Wasternack, C. (2007) Jasmonates: an update on biosynthesis, signal transduction and action in plant stress response, growth and development. Ann Bot. 100(4), 681-97.

Yamaguchi-Shinozaki, K. and Shinozaki, K. (2005) Organization of cis-acting regulatory elements in osmotic- and cold-stress-responsive promoters. Trends Plant Sci. 10, 88-94.

Yoshida, K., Igarashi, E., Mukai, M., Hirata, K. and Miyamoto, K. (2003) Induction of tolerance to oxidative stress in the green alga, Chlamydomonas reinhardtii, by abscisic acid. Plant Cell Environ. 26, 451-457.
Zeller, G., Henz, S.R., Widmer, C.K., Sachsenberg, T., Ratsch, G., Weigel, D. and Laubinger, S. (2009) Stress-induced changes in the Arabidopsis thaliana transcriptome analyzed using whole genome tiling arrays. Plant J. 58, 1068-1082.

Zlatve, Z. and Yordanov, I. (2004) Effects of soil drought on photosynthesis and chlorophyll fluorescence in bean plants. Bulgarian. J. Plant Physiol. 30, 3-18.

Zou, J., Abrams, G.D., Barton, D.L., Taylor, D.C., Pomeroy, M.K. and Abrams, S.R. (1995) Induction of lipid and oleosin biosynthesis by (+)-abscisic acid and its metabolites in microspore-derived embryos of Brassica napus L. cv Reston. Plant Physiol. 108, 563-571.

Zou, J.J., Li, X.D., Ratnasekera, D., Wang, C., Liu, W.X., Song, L.F., Zhang, W.Z. and Wu, W.H. (2015) Arabidopsis calcium-dependent protein kinase 8 and catalase 3 function in abscisic acid-mediated signaling and $\mathrm{H}_{2} \mathrm{O}_{2}$ homeostasis in stomatal guard cells under drought stress. Plant Cell. 27, 1445-60.

(Received 20/4/2017 accepted $8 / 1 / 2018$ ) 


\section{دراسة التأثيرات التفاعلية للكالسيوم وحمض الأبسيسيك على بادرات القمح المُجهدة بالجفاف

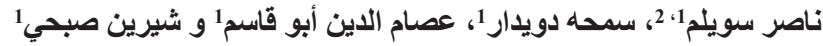

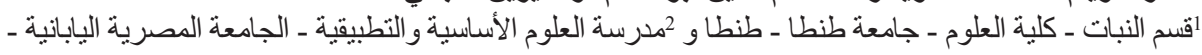

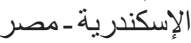

يمثل الجفاف و احداً من الإجهادات البيئية التي تسبب أضر اراً بالغة لنمو وإنتاجية النباتات. يهتم هذا البحث بدر اسة

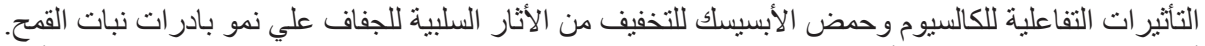

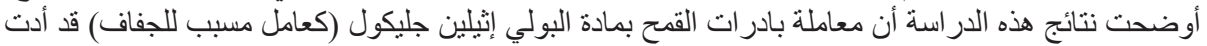

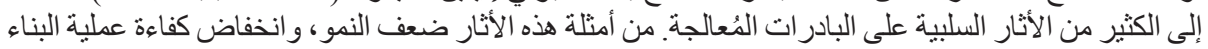

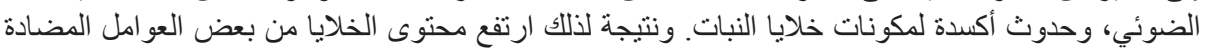

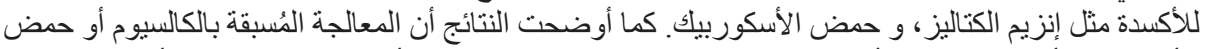

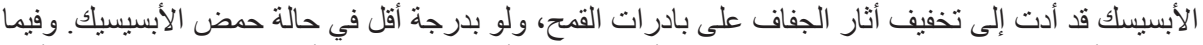

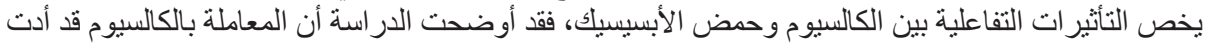

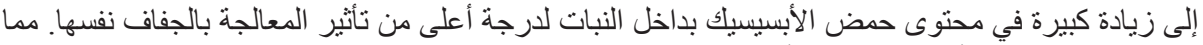

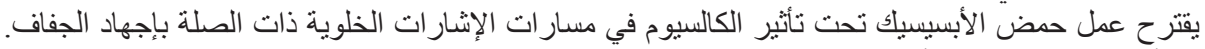

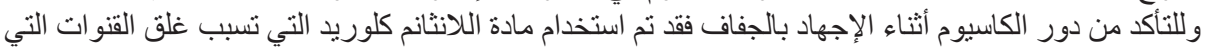

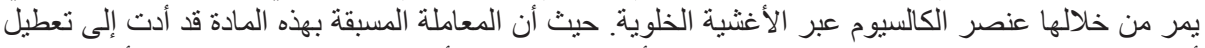

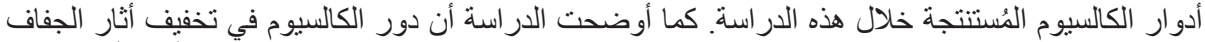

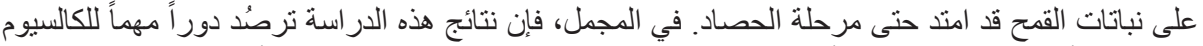

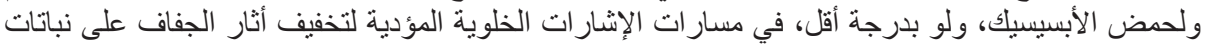
المحاصبل وتحسين انتاجيتها. 